\title{
Evidence-based dentistry - The London Symposium
}

\section{Derek Richards}

\author{
Director, Centre for Evidence-based Dentistry, Oxford, UK
}

\section{Despite the amount of information available, the limited amount of resources available for research within dentistry makes collaboration both between institutions and across country boundaries important.}

In early November the School of Oriental and African Studies in London hosted an important gathering of dentists from 11 countries. They met to discuss the challenge of developing and expanding the evidence-based approach in dentistry.

Professor Bill Shaw opened the symposium with an outline of the evidencebased approach indicating the challenges ahead. Dr Richard Niederman, who heads the Office of Evidence-Based Dentistry at Harvard School of Dental Medicine, outlined the activities in the USA to date and their development plans for the next 3 years. The work of the International Collaborative Cochrane Oral Health Group which is currently based at Manchester Dental School in the UK was described by Dr Helen Worthington who, with Professor Shaw, is one of the Co-ordinating Editors of the Oral Health Group.

Professor Nigel Pitts presented an overview of UK activity in primary care research including primary dental care. This was followed by Professor Elizabeth Treasure discussing the challenges of linking Primary Care dentistry and the Universities. Mr Derek Richards from the Centre for Evidence-based Dentistry outlined the stages of evidence-based dentistry and the skills gap, which needs to be addressed to enable dentists to practise evidencebased dentistry.
The practicalities of disseminating and implementing research findings were considered by Dr Chris Deery. Those that are consistently effective are: educational outreach, involving one to one contact, reminders in patient notes, interactive educational meetings, multifaceted interventions, computeraided reminders and financial incentives and disincentives, although the evidence here is limited. The morning session was concluded by Dr Richard Watt who, taking the example of the reviews on the effectiveness of oral health promotion, considered problems in applying the evidence-based approach.

Dr Jan Clarkson introduced the afternoon workshop sessions, which covered three main areas.

- Teaching and Training

- Research

- Dissemination Implementation

It was recognised that, at present, the skills required for teaching, training, research dissemination and implementation of the evidence-based approach in dentistry are lacking. The development of the skills is a challenge for the profession as the 'conservative' approaches and organisational barriers to change both within the structure of dental schools and the profession can be considerable. The current focus of dental schools leans toward the teach- ing of technical skills rather than scientific thinking led as much by regulatory bodies as a belief in the traditional methods of teaching and training. The conflict between the perceived need for teaching certainty to students and the wide variation in diagnosis, decision making and treatment planning could be addressed by the evidence-based model which accepts uncertainty.

However, the winds of change are beginning to blow through the profession with educationalists and leading professionals seeking to introduce evidence- and problem-based learning into curricula. The opportunities, which continued professional development and a move to the lifelong learning approach present, need to be capitalised on. This is made easier with rapid increase in the availability of information through the Internet and expansion of computer literacy. This explosion of information could result in the individual being further swamped by information. To counter this the development of evidence-based information by a range of bodies - the Centre for Evidence-based Dentistry (CEBD), The Cochrane Oral Health Group, the National Institute of Dental and Cranio-facial Research (NIDCR), The National Institute of Clinical Excellence (NICE), and journals of secondary publication - will filter the information for the individual.

The availability of the information does not, however, mean that people are aware of it or use it in their everyday practice. Dissemination and implemen- 
tation are important elements and much is known about changing professionals behaviour. Early introduction of the appropriate skills in the undergraduate curriculum is important, as is appropriate funding for implementation when guidelines for new treatments or recommendations are introduced.

Despite the amount of information available, the limited amount of resources available for research within dentistry makes collaboration both between institutions and across country boundaries important. This is already happening with the Cochrane Oral Health Group and should be encouraged for other evidence-based activities within dentistry. The London Sympo- sium and meetings held at the IADR meeting in Vancouver in 1999 are the beginnings of what could become an important endeavour for dentistry.

A more detailed list of the feedback from the workshop is available at the Centre for Evidence-based Dentistry website at: http://www.ihs.ox.ac.uk/ cebd/sympfeed.htm.

\section{Our contact with you is vital...}

\section{EBD is a channel between research and practice in dentistry. Use your expertise to contribute to our commentaries. If you.}

Are engaged in clinical practice in one or more of the disciplines of relevance to target audiences of EBD...

Can respond within 2 weeks of our request for a commentary...

Can write clearly in English...

Have working knowledge of the basic principles of evidence-based healthcare...

\section{then contact us...}

Derek Richards, Editor, c/o Katy Christomanou, Publisher

Evidence-Based Dentistry, Nature Publishing Group, Houndmills, Basingstoke, Hampshire, RG21 6XS, UK

Tel: +44 (0) 1256302855 Fax: +44 (0) 1256354018 E-mail: ebdeditor@nature.com 